\title{
An Angular Kinematical Analysis of Soccer Instep and Inside Kick at Impact Phase of University Soccer Players
}

\author{
Mohammad Ahsan* \\ Assistant Professor, Department of Physical Therapy, College of Applied Medical Sciences, Imam Abdulrahman
} Bin Faisal University, Dammam (KSA)

*Corresponding Author: Mohammad Ahsan, Assistant Professor, Department of Physical Therapy, College of Applied Medical Sciences, Imam Abdulrahman Bin Faisal University, Dammam (KSA)

\begin{abstract}
The kicking skills in soccer have a complex motor movement with assisted by of whole body segments and joints. The purpose of this research was to determine and enlighten the kinematical determinants of soccer instep and inside foot kick at impact phase. Twenty male soccer players were recruited for this study from Lautoka campus of Fiji National University, Fiji. Participants delivered instep and inside of the foot kick with their dominant (right) foot. Each player executed three trails of each kicks with a stationary ball. Two video cameras were used for this study. The sampling rates of the cameras were 60 frames per second. For identification purposes, a number was given for each trail. The best trail kicks were identified and edited for analysis. The identified trails were played with the Kinovea Software to get the angular movement of lower extremity joints. For statistical analysis IBM SPSS was used to determine descriptive analysis, analysis of variance and t-test to detect a mean difference between joints (Ankle, Knee, and Hip) of instep and inside of foot kicks. The findings of the study have confirmed that the angle of ankle and hip joints are insignificant between instep and inside foot kick at impact phase, whereas the angle of the knee joint is differed significantly between instep and inside foot kick of university players. The result also revealed that hip joint showed significant difference with ankle and knee joint angle. Whereas there is no significant mean difference found between ankle and knee joint angle for instep kicks. For the inside foot kick, the result showed that there are significant mean differences among ankle, knee, and the hipjoint angle at impact phase. The knowledge of details regarding kinematic parameters of impact phase would be helpful to the coach and the player in obtaining better performances.
\end{abstract}

Keywords: Soccer, Instep Kick, Inside Kick, Impact Phase, Angular Kinematics

\section{INTRODUCTION}

Kinematic of soccer kick has been characterized by the interface between segment and joint without the cause of force during the execution. The kicking skills in soccer have a complex motor movement with assisted by of whole body segments and joints. Although there are many variations of a kick in a soccer game due to nature, the intent of kick, position and ball speed. Each kick used by the soccer players for a specific purpose that leads to winning the game. The variant which has been reported in the literature is the instep kick, such as when passing a ball at a long and medium distance, performing penalty kicks and shooting at the goal (Kellis and Katis, 2007).Considering its complexity, application in the game, multiple advantages and the desire for the best possible technical performance, the soccer kick is the subject of much research that has involved all levels of players, from youth athletes to experience professionals' players (Barfield et al., 2002; Reilly, 2003; Ismail et al., 2010; Kellis et al., 2004).

There are many researcher and scholars whose indulge in advance kinematic and kinetic studies to measure and determine various factors those are positively or negatively associated with the soccer performance. There are numbers of studies have focused on the instep and inside foot kicks (Asami, et al. 1976; Togari. 1983; Levanon\&Dapena, 1998; lees \& Nolan, 2002; Asai, et al. 2004; Carre\&Asai, 2004). Ball and foot velocities, angles of approach and foot and ball surface contact were considered as major determinants of performance. Certain kinematic parameters appear to be identical during the execution of instep and inside foot kick, but the resultant might be different. Conventionally, many researchers classified soccer kicks into three phases 1. Initial Phase (Loading), 2. Impact Phase (Foot contact with the ball) 3. Follow Through (Recovery) Phase (Lees and Nolan, 1998; Barlett, 2006; 
Kellis and Katis, 2007). All these phases have their kinesiological and biomechanical characteristics. It has been found that each and every phase is interconnected with its mechanical properties (Barlett, 2006). During the soccer kick, the impact phase is the only phase where the optimum forces exerted by the player with the consideration of the situation. This force should be resultant for the direction, trajectory, and velocity of the soccer ball. Thus, the impact phase (ball to foot) has been found to be important in soccer kicking (Nunome et al., 2006).

There isa number of studies are documented in regard to soccer instep kick, in contrast to this mechanics of inside foot kick particularly at impact phase has been narrowly described. Therefore, the purpose of this investigation was to determine and enlighten the kinematical determinants of soccer instep and inside foot kick at impact phase. The knowledge of details regarding kinematic parameters of impact phase would be helpful to the coach and the player in obtaining better performances.

\section{Materials AND Methodology}

\subsection{Participants}

Twenty male soccer players were recruited for this study from Lautoka campus of Fiji National University, Fiji. All the soccer players had a minimum of three years playing experience at this level. The characteristics of the soccer players are as: Age $=19.42 \pm 2.31$ years, body height $=162.64 \pm$ $8.54 \mathrm{~cm}$., weight $=58.4 \pm 12.45 \mathrm{~kg}$., and BMI $=22.96 \pm 4.56 \mathrm{~kg} / \mathrm{m}^{2}$. Participants delivered instep and inside of the foot kick with their dominant foot i.e. right foot. All the players were readily volunteered to act as participants for this study.

\subsection{Preparation of Participants}

All the players wore complete soccer kit to execute the soccer kicks. Prior to the main test, they completed an adequate general and specific warm-up. Players also undertook practice instep and inside of the foot kick.

\section{BIOMECHANICAL ANALYSIS}

\subsection{Camera Set-up}

To obtain maximum accuracy in the reconstruction of two-dimensionalcoordinates, two video cameras (Sony HDR-C-CX200) were used for this study. The cameras were set-up on the rigid tripods. The cameras were placed in such a way that the optical axes of the cameras intersect on the sagittal and frontal plans perpendicularly. The first camera placed perpendicular to the sagittal plane so that the players' leg gives $90^{\circ}$ angle between their respective optical axes. The second camera was placed on the frontalplane. The height of the cameras was 1 meter from the ground.

\subsection{Camera Speed and Sync}

The sampling rate of the cameras were 60 frames per second. The shutter speeds of the cameras were $1 / 1000$ of a second in order to eliminate the blurring effect of video recording.

\subsection{Data Reduction}

As the video recording processes were over, the video recordings were loaded into the personal laptop to trail identification. For identification purposes, a number was given for each trail. The best trail kicks were identified and edited for analysis. The identified trails were played with the Kinovea Software.

\subsection{Experimental Setup}

The trial was conducted on a sunny and clear weather on an outdoor soccer field with natural grass. The average wind velocity and temperature were $0.75 \mathrm{~m} / \mathrm{s}$ and $21.37^{0}$ Celsius respectively. Each player executed three insteps and three inside of foot kicks of a stationary ball. The length of the approach was self-selected by the players. Kinovea0.8.15 software was used to determine the kinematics of soccer instep and inside of the foot kick at the impact phase only.

\subsection{Statistical Analysis}

To test the objective of the study descriptive analysis statistics (Mean, standard deviation, minimum, and maximum) was used for describing the data and nature of the data obtained on the samples. 
Repeated measure analysis of variance (ANOVA) also used to detect a mean difference between joints (Ankle, Knee, and Hip) of instep and inside of foot kicks. For this purpose, Statistical Package for Social Sciences (IBM SPSS) version 23 was used. The significance was set at 0.05 levels.

\section{RESUlts}

\subsection{Statistics of Ankle, Knee, and Hip Joint Angles of Instep and Inside Foot Kick at Impact Phase.}

Table1. One-way ANOVA

\begin{tabular}{|c|l|c|c|c|c|}
\hline \multicolumn{2}{|c|}{} & SS & df & MS & F \\
\hline \multirow{3}{*}{ Instep } & Between Groups & 4657.885 & 2 & 2328.942 & 6.787 \\
\cline { 2 - 6 } & Within Groups & 19559.182 & 57 & 343.144 & \\
\cline { 2 - 6 } & Total & 24217.067 & 59 & & 14.573 \\
\hline \multirow{3}{*}{ Inside } & Between Groups & 2689.225 & 2 & 1344.613 & \\
\cline { 2 - 6 } & Within Groups & 5259.226 & 57 & 92.267 & \\
\cline { 2 - 6 } & Total & 7948.451 & 59 & & \\
\hline
\end{tabular}

The result of the ANOVA revealed that the calculated value of $F=6.787$ and 14.573 are significant during the impact phase of instep and inside kicks respectively. Thus, the least significant difference (LSD) has been calculated to determine the existence of a significant difference between ankle, knee, and hip joint during the impact phase of instep as well as inside foot kick.

\subsection{Post Hoc Tests (LSD)}

Table2. Multiple Comparisons

\begin{tabular}{|c|c|c|c|c|c|}
\hline Dependent Variable & (I) Joints & (J) Joints & Mean Difference (I-J) & Std. Error & Sig. \\
\hline \multirow[t]{6}{*}{ Instep } & \multirow[t]{2}{*}{ Ankle } & Knee & -8.98470 & 5.85785 & .131 \\
\hline & & Hip & -21.48640 & 5.85785 & .001 \\
\hline & \multirow[t]{2}{*}{ Knee } & Ankle & 8.98470 & 5.85785 & .131 \\
\hline & & Hip & $-12.50170^{*}$ & 5.85785 & .037 \\
\hline & \multirow[t]{2}{*}{ Hip } & Ankle & $21.48640^{*}$ & 5.85785 & .001 \\
\hline & & Knee & $12.50170^{*}$ & 5.85785 & .037 \\
\hline \multirow[t]{6}{*}{ Inside } & \multirow[t]{2}{*}{ Ankle } & Knee & $-10.04650^{*}$ & 3.03755 & .002 \\
\hline & & Hip & $-16.24790^{*}$ & 3.03755 & .000 \\
\hline & \multirow[t]{2}{*}{ Knee } & Ankle & $10.04650^{*}$ & 3.03755 & .002 \\
\hline & & Hip & $-6.20140^{*}$ & 3.03755 & .046 \\
\hline & \multirow[t]{2}{*}{ Hip } & Ankle & $16.24790^{*}$ & 3.03755 & .000 \\
\hline & & Knee & $6.20140^{*}$ & 3.03755 & .046 \\
\hline
\end{tabular}

*The mean difference is significant at the .05 level.

The comparison of Least Significant Difference (LSD) for a mean of instep and inside foot theick during impact phase has been computed and presented in table-III. The table revealed that hip joint showed a significantdifference, with ankle the and knee joint angle. Whereas there is no significant mean difference found between ankle and knee joint, angle for instep kicks. For the inside foot kick, the table showed that there are significant mean differences among ankle, knee, and the hipjoint angle at impact phase.

Table3. Paired Samples Statistics

\begin{tabular}{|c|c|c|c|c|c|}
\hline \multirow{2}{*}{$\begin{array}{c}\text { Instep v/s } \\
\text { inside }\end{array}$} & \multicolumn{3}{|c|}{ Paired Differences } & \multirow{2}{*}{$\mathbf{t}$} & \multirow{2}{*}{ Sig. } \\
\hline & Mean & SD & df & & \\
\hline Ankle & -6.95 & 25.11 & 19 & -1.238 & .231 \\
\hline Knee & -8.01 & 11.89 & 19 & -3.011 & $.007 *$ \\
\hline Hip & -1.71 & 11.10 & 19 & -.690 & .499 \\
\hline
\end{tabular}

*The mean difference is significant at the .05 level

The table reveals that the comparison of paired differences between ankle, knee, and hip of instep and inside foot kick of university players. This statistical finding exhibit that the angle of ankle and hip joints are insignificant between instep and inside foot kick at impact phase, whereas the angle of the knee joint is differed significantly between instep and inside foot kick of university players. 


\section{DISCUSSION}

As per the finding of the results in this study, there is a significant difference between instep and inside kicks at impact phase within the group and between groups. Result also revealed that hip joint showed significant difference with ankle and knee joint angle. Whereas there is no significant mean difference found between ankle and knee joint angle for instep kicks. For the inside foot kick, there are significant mean differences among ankle, knee, and the hipjoint angle at impact phase. There are some studies which revealed that the plantar flexion at ankle joint has a significant difference between ball contacts and take off phase (Levanon and Dapena, 1998). Literature has shown that players performed an instep kick, impact the ball at around $22^{\circ}$ to $27^{\circ}$ (Lee and Nolan, 1998). A great impact of the foot with ball helps to ankle during plantar flexion and it will continue until the joint reach at their complete range of motion (Lees, 1996). According to Noland and Feeley (2017) angle of the hip joint have a greater range of motion in experience players as compare with novice players, 129 and 164 degrees respectively. The earlier studies suggest the knee joint and ankle joint angles do not influence much in certain types of kicks. The result showed significant differences during the soccer kick by many players when they control their range of motion at the knee joint and ankle joint according to their need.

The results reveal that the comparison of paired differences between ankle, knee, and hip of instep and inside foot kick of university players. These statistical findings exhibit that the angle of ankle and hip joints are insignificant between instep and inside foot kick at impact phase, whereas the angle of the knee joint is differed significantly between instep and inside foot kick of university players. Shan \&Westerhoff (2005) found that there are significant differences exist at the ankle, knee and hip flexion-extension between experience and novice players. The range of motion for ankle, knee and hip flexion-extension is increased while the ankle abduction-adduction decrease in both groups, it is confirming that the stability at the ankle joint to be equivalently required during kicking. As the hip joint angle is instrumental in the force producing in the kick. Thus, all level of players hasa similar angle of motion to produce maximum impact force on the ball, maybe because of this reason, the hip angle of different level players has not shown the significant difference. According to Dorge et al. (2002), it is evidence that skillful soccer players have movement control at the knee and hip joint with contact phase during the soccer kick. There is a significant difference between the two levels of players. The statistical description indicates that the kicking movement starts with the hip joint, knee joint, and ankle joint while finish with the acceleration of foot. Sakamoto et al. (2010) find in their studies that there is the statistically significant difference between instep and inside kick, the values for the inside kick is higher than the instep kick. The inside kicks have less effect on the plantar-dorsal flexion due to the ball surface contact with the foot at impact phase. Besidesthis, the impact it simple to hit the ball from the center of the ankle joint during instep kicks. They also find that the female players similarly have better values for inside kicks as compare with instep kicks. Shinkaiet al (2009) have found in their study that there is a less abduction movement and greater plantar flexion movement of the foot during instep kick at impact phase. They perform three-dimensional movements of the foot different types of maximum instep kick with several ball contact positions.

\section{CONClusion}

Current research has confirmed that the angle of ankle and hip joints are insignificant between instep and inside foot kick at impact phase, whereas the angle of the knee joint is differed significantly between instep and inside foot kick of university players. The result also revealed that hip joint showed significant difference with ankle and knee joint angle. Whereas there is no significant mean difference found between ankle and knee joint angle for instep kicks. For the inside foot kick, the result showed that there are significant mean differences among ankle, knee, and the hipjoint angle at impact phase. It was determined that the interaction of kicking foot and ball at impact phase is very influential. The findings of the study should be obliged to develop an understanding that uncovers the success of different kicks. Sophisticated and more advanced instruments would allow for a more precise evaluation of soccer kick skill at different phases. Soccer kick is continuing research topic to improve teaching, training, technique, prevent injuries, and performance.

\section{REFERENCES}

[1] Asai, T., Takano,S., M.J. \&Haake, S.J. (2004).A fundamental study of an infront curve kick in football, The engineering of Sports. R. M. a. JM. PallisEds, ISEA. 5: 290-295. 
[2] Asami, T., Togari, H. \& Kikuchi T. (1976). Energy efficiency of ball kicking, Biomechanics. P. V. Komi. Baltimore, University Park Press. V-B: 135-140.

[3] Barfield, RW, Kirkendall TD., Yu B. (2002). "Kinematic instep kicking differences between elite female and male soccer players.". Journal of Sports Science and Medicine 1: 72-79.

[4] Barlet, R. (2006). Sports Biomechanics: Reducing injury and improving performance. An imprint of Routledge, London, and New York.

[5] Carre, MJ. \&Asai. T. (2004). Biomechanics and aerodynamics in soccer. In: Biomedical Engineering Principles in Sports, edited by Hung, G.K., andPallis, J.M. (New York: Kluwer Academic Plenum Publishers) 333-364.

[6] Dorge, HC., Andersen, TB., Sorensen, H., \& Simonsen, EB. (2002). Biomechanical differences in soccer kicking with the preferred and the non-preferred. Journal of Sports Science 20: 293-299.

[7] Ismail AR., Mansor MRA., Ali MFM., Jaafar S,\&Makhtar NK. (2010). Biomechanical Analysis of Ankle Force: A Case Study for Instep Kicking. American Journal of Applied Sciences 7(3): 323-330. DOI: 10.3844/ajassp.2010.323.330.

[8] Kellis E, Katis. A.,\&Gissis I. (2004). Knee biomechanics of the support leg in soccer kicks from three angles of approach." Medicine \& Science in Sports Exercise. 36(6): 1017-1028.

[9] Kellis, E.\&Katis, A. (2007). "Biomechanical characteristics and determinants of instep soccer kick." Journal of Sports Science and Medicine 6: 154-165.

[10] Lees, A.\& Nolan, L. (2002). Three-dimensional kinematics analysis of instep kicks under speed and accuracy conditions. In W. Spink, T. Reilly, \& A. Murphy (Eds.) Science and football IV, London, England: Routledge, 16-21.

[11] Lees, A. (1996). Biomechanics applied to soccer skills. In Science and Soccer (edited by T. Reilly), E \& FN Spon, London. 123-133.

[12] Lees, A., Nolan, L. (1998). The biomechanics of soccer: A review. Journal of Sports Science 16 (3) 211 234.DOI: $10.1080 / 026404198366740$.

[13] LevanonJ.\&Dapena J. (1998). "Comparison of the kinematics of the full-instep and pass kicks in soccer." Medicine \& Science in Sports \&Exercise 30(6): 917-927.

[14] Noland S. \&Feeley J. (2017). The in-step soccer kick; novice vs. experienced player. http;//www.umich .edu/ mvs330/f01soccer/main.html Retrieved 23 Feb 2017.

[15] Nunome H., Lake M., Georgakis A. \&Stergioulas L. (2006). Impact phase kinematics of instep kicking in soccer. Journal of Sports Sciences 24 (1), 11-12. DOI: 10.1080/02640410400021450.

[16] Nunome, H., Georgakis, A., Shinkai, H., Saito, H., Tsujimoto N. and Ikegami Y. (Tuesday 3 July 2007). "Impact Phase Kinematics of Side-Foot and Instep Soccer Kick." Journal of Biomechanics 40(S2) XXI ISB Congress, Podium Sessions. S214 DOI: 10.1016/S0021-9290(07)70210-5.

[17] Reilly T., (2003). Environmental stress. In Science and Soccer, 2nd ed, edited by Reilly, T.and Williams, A.M. (London: Routledge). Taylor \& Francis Group123-125.

[18] Sakamoto K., Geisler G., Nakayama M., \&Asai T. (2010). Kinematics of the foot joint in female soccer players during the ball impact phase of kicking. Science Direct; Procedia Engineering 2 (2): 2549-2554 DOI: 10.1016/j.proeng.2010.04.030.

[19] Shan, G. \&Westerhoff P. (2005). Full-body kinematic characteristics of the maximal instep soccer kick by male soccer players and parameters related to kick quality soccer. Journal of Biomechanics 4(1): 5972.DOI: $1080 / 14763140508522852$.

[20] Shinkai H., Nunome H., Isokawa M. \&Ikegame, Y. (2009). Ball impact dynamics of instep soccer kicking. Journal of medicine \& science in sports \& exercise 41(4):889-897. DOI: 10.1249/MSS.0b013e31818e804 4

[21] Togari, H. (1983). Biomechanical study of kicking power in soccer. Descente sports science 4: 241-250 (in Japanese with English abstract).

Citation: Mohammad Ahsan. "An Angular Kinematical Analysis of Soccer Instep and Inside Kick at Impact Phase of University Soccer Players" International Journal of Sports and Physical Education (IJSPE), vol 4, no.3, 2018, pp. 1-5. doi:http://dx.doi.org/10.20431/2454-6380.0403001.

Copyright: (C) 2018 Authors. This is an open-access article distributed under the terms of the Creative Commons Attribution License, which permits unrestricted use, distribution, and reproduction in any medium, provided the original author and source are credited. 